\title{
Degradation of Polyethylene and Biocomponent-Derived Polymer Materials: An Overview
}

\author{
M. Mierzwa-Hersztek ${ }^{1}\left[\right.$ C $\cdot$ K. Gondek ${ }^{1} \cdot$ M. Kopeć ${ }^{1}$
}

Published online: 21 January 2019

(c) The Author(s) 2019

\begin{abstract}
The progressing degradation of the natural environment taking place over the last few decades and resulting from the systematically growing production of synthetic polymer materials led to the search for technological innovations aimed at producing environmentally friendly materials. Moreover, the increasing importance of sustainability promotes the development of bio-based and biodegradable polymers, sometimes misleadingly referred to as "bioplastics". Inability to degrade synthetic polymer materials and the problem of their persistence in the environment even for hundreds of years have caused the production of polymer materials with the addition of components that may accelerate their degradation more and more important in recent years. Additionally, the growing interest in environmental issues makes the requirements for new materials that will not significantly burden the environment higher. In Poland $29.1 \%$ and $26.8 \%$ of post-consumer polymer materials, respectively, were recovered and recycled, which means that up to $44.1 \%$ of post-consumer polymer materials were sent to municipal landfills. In 2017, for the first time in Poland, more plastics were recovered (55.9\%) than stored (44.1\%). However, by 2020 , the level of energy recovery and recycling of post-consumer polymer materials in Poland should cover a total of $84.5 \%$. When looking at the average values for Europe (recycling 31.1\%, recovery $41.6 \%$, storage $27.3 \%$ ), it should be noted that Poland has much to catch up in this area and decisive actions should be taken to actually solve this problem. For this reason, it is extremely important to know the mechanisms responsible for the degradation of polymer materials and understand the interaction between these materials and abiotic and biotic factors that cause structural changes in polymers. Recent studies show that knowledge of the conditions determining the decomposition of polyethylene polymer materials and their impact on the natural environment is still insufficient. The literature reports reveal many contradictory theories, especially those that relate to the degradation of polymer materials in the soil environment. This study constitutes a comprehensive review of researches on (bio)degradation of polymer materials over the last decades, various methods of polymer structure modification to increase the degree of their degradability, as well as methods of recycling post-consumer polymer materials. Because there is a need to assess the performance of polymer innovations in terms of their biodegradability, especially under realistic waste management and environmental conditions, to avoid the unwanted release of plastic degradation products to the environment.
\end{abstract}

M. Mierzwa-Hersztek

monika6_mierzwa@wp.pl; monika.mierzwa@urk.edu.pl

1 Department of Agricultural and Environmental Chemistry, University of Agriculture in Krakow, al. Mickiewicza 21, 31-120 Kraków, Poland 


\section{Graphical Abstract}



Keywords Sustainable development $\cdot$ Polymer materials $\cdot$ Polyethylene $\cdot$ Corn starch $\cdot$ Degradation $\cdot$ Recycling

\section{Introduction}

Polymers are macromolecular compounds that consist of macromolecules built from repeated structural units (mers). They are usually a mixture of compounds (homologs) with different chain length, i.e. compounds of different molecular weights $[1,2]$. Molecular weight is an important feature that determines the properties of a polymer and is closely related to polymerisation, i.e. one of the ways of macromolecular compound formation. The polymer polymerisation degree is a non-nominal number informing about how many times a particular element (mer) is repeated in the structure of a molecular compound [2-5]. In practice, three main methods of monomer polymerisation are known and used: radical polymerisation (initiated by organic low molecular substances), ionic (initiated by anions and cations), and coordination polymerisation (initiated by transition metal atoms, surrounded by ligands) $[6,7]$. Considering the above, it can be concluded that the structure of the resulting polymer can be controlled by choosing the appropriate polymerisation conditions and initiators. Many authors emphasise that the spatial structure of a polymer is very important for its properties, as it decides, among others, about its density, thermal stability, and mechanical strength $[1,3,8]$. However, the use of polymers with unmodified and singlecomponent structures is currently relatively rare. Polymers generally contain numerous auxiliary substances that give them the desired characteristics and, in this form, they are called polymer materials. The most common auxiliary substances used in the production of polymer materials are: anti-aging and cross-linking agents, softeners, dispersants, activators, and fillers [9].

By origin, polymers are divided into: natural polymers (biopolymers), synthetic polymers (obtained by chemical synthesis), and modified polymers (natural or synthetic polymers whose structure was chemically or physically changed) $[1,4,5]$. Natural polymers are an indispensable element of the animate world (e.g. carbohydrates, proteins, fats, nucleic acids, cellulose, starches, oils), and are subject to natural decomposition processes in the environment (photodegradation, chemical degradation, mechanical degradation, biodegradation). These processes take place simultaneously and complement each other [1]. In turn, synthetic polymers are produced mainly from petrochemical feedstocks (crude oil, natural gas), and usually constitute a foreign body in the environment, whose decomposition can last from dozens to even hundreds of years. It is estimated that synthetic polymers are nearly $98 \%$ of currently produced polymer materials, of which over $80 \%$ is produced by the petrochemical industry $[2,10]$.

\section{Literature Review}

Over the past decades, there has been a progressive intensification of the production and use of polymer materials [10, 11]. Literature data show that since 1950 , global production of polymer materials has increased from 1.3 to 335 million tonnes in 2017, and the forecasted increase in their production in the following years will be approx. $1.5-2.5 \%$ per year 
[12]. The dynamic increase in the production of polymer materials is closely related to their widespread and multidirectional use in many branches of the economy $[13,14]$. In addition, simple processing by which polymer materials are obtained, as well as low prices of products that significantly improve the quality and comfort of life have made these materials become popular products of everyday use. Due to their diversity, polymer materials have a wide range of physicochemical properties that make them increasingly replace the wood, glass, and wood packaging used so far.

Since the first synthetic polymer materials have been obtained, technological progress has focused primarily on improving the synthesis methods in order to obtain a product of high durability, resistance to external factors and, above all, good functional properties $[10,15]$. Unfortunately, the beneficial functional characteristics of polymer materials become their disadvantage after their use, and the disposal of their waste creates very serious problems $[5,16]$. Frequently, the problem is compounded by the significant diversification of waste going to municipal landfills. According to data published by PlasticsEurope [12], storage remains the dominant way of neutralising post-consumer polymer materials in many countries of the European Union. Also, the National Waste Management Plan (NWMP) [16] reveals that the management of post-consumer polymer materials in Poland is still ineffective. However, in 2016, 29.1\% and $26.8 \%$ of these materials, respectively, were recovered and recycled, which means that up to $44.1 \%$ of post-consumer polymer materials were sent to municipal landfills. In 2017, for the first time in Poland, more plastics were recovered $(55.9 \%)$ than stored $(44.1 \%)$. As it results from the NWMP [17], by 2020, the level of energy recovery and recycling of post-consumer polymer materials should cover a total of $84.5 \%$. When looking at the average values for Europe (recycling $31.1 \%$, recovery $41.6 \%$, storage $27.3 \%$ ), it should be noted that Poland has much to catch up in this area and decisive actions should be taken to actually solve this problem. Currently, the share of polymer materials in the mass of waste taken to landfills in Poland is $15.5 \%$ [17] (Fig. 1). According to PlasticsEurope [12], over 3.5 million tonnes of polymer materials were used in Poland in 2017 (nearly $75 \mathrm{~kg}$ per capita). In this respect, Poland was classified 6th among the European Union member states. However, it should be noted that the growth rate of the polymer material consumption in Poland is clearly higher that the EU average value.

Polymer material waste is considered one of the most onerous waste $[11,18]$, constituting an enormous threat to the natural environment $[4,14,16]$. For this reason, recycling of polymer materials is currently one of the most important waste management problems [5, 10, 15]. As it was mentioned above, the management and disposal of post-consumer polymer materials in the European Union member states is currently implemented by three methods: recycling, energy recovery, and storage. At the same time, according to the applicable trends related to the methods of polymer material waste management, it is recommended to

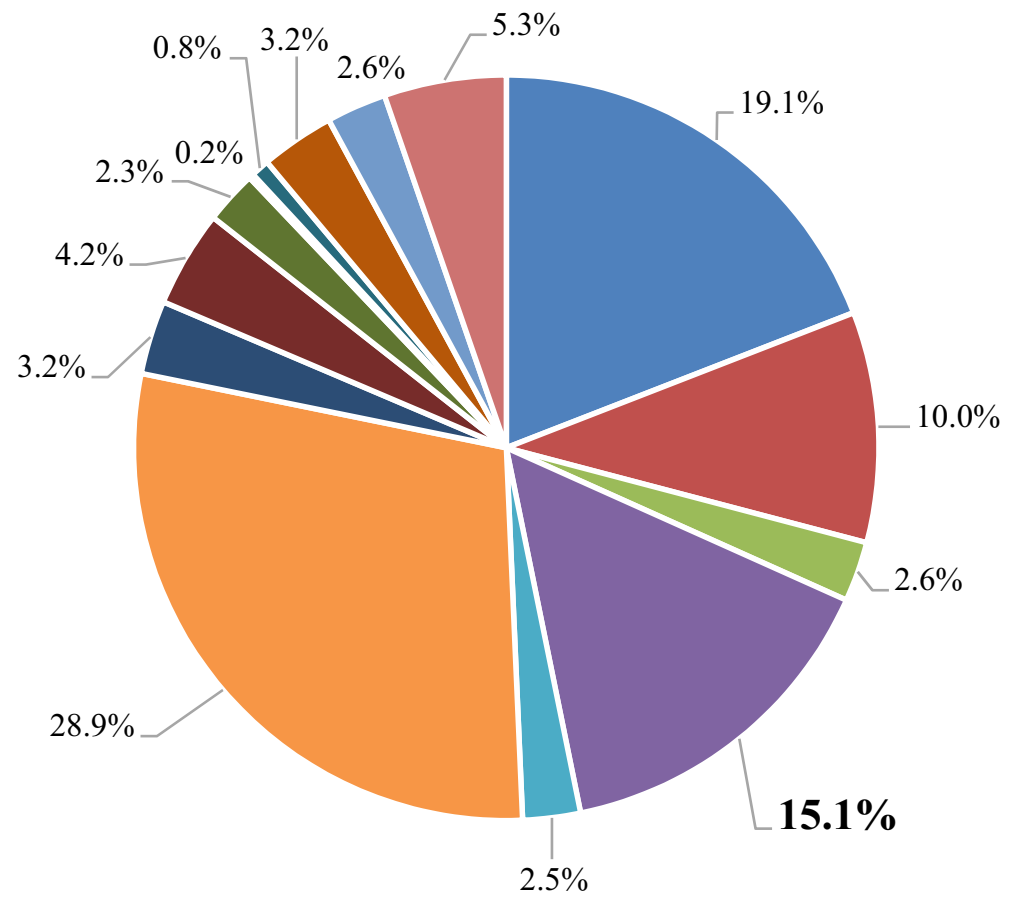

- Paper and cardboard

- Glass

- Metals

- Polymer materials

- Multi-material waste

- Kitchen and garden waste

- Mineral wastes

- Fraction $<10 \mathrm{~mm}$

- Fabrics

- Wood

- Hazardous waste

- Other categories

- Large-size waste

Fig. 1 The morphological composition of municipal waste in Poland [17] 
subject them to chemical recycling (e.g. fuel oil production), feedstock recycling (processing into feedstocks from which these materials were made) or material recycling (fragmentation - applies only to clean and homogeneous materials) [19]. These methods are somewhat different approach from the waste hierarchy recommended by the European Union authorities (in order from most to least desirable): prevention, reuse, recycling, disposal [20].

Problems related to environmental protection, relatively expensive methods of recycling synthetic polymer materials, as well as sustainable development aspects have changed the image of multidirectional functionality of polymer materials in recent years. Therefore, at present, intensive scientific studies are being carried out worldwide in many research and development facilities, aimed at finding technologies for the production of environmentally-friendly polymer materials, while maintaining their current functions $[5,11,14$, 21, 22].

Nowadays, polyethylene (PE) is one of the most popular and most widely used polymer in the world $[8,10]$. Due to its specific functional properties, this polymer has become commonly used in the production of various packaging materials. Unfortunately, after a relatively short time of use, it becomes extremely resistant to biodegradation, constituting a burden on the environment. The polyethylene's resistance to degradation results from the high molecular weight of this polymer and its content of antioxidants and stabilisers $[9,10]$. According to these authors, the addition of these substances protects polyethylene against oxidation already at the production stage. Pająk et al. [8] and Szumigaj-Tarnowska [21] reported that the resistance of polyethylene to degradation is higher compared to other thermoplastics and it is increased even more by the absence of heteroatoms and double bonds in the chain.

\section{Methods to Accelerate the Degradation of Polyethylene Polymer Materials}

One way to accelerate the degradation of polyethylene is the use of the so-called prooxidants (prodegradants) added in the amount of $1-5 \%$, which initiate and propagate free-radical chain reactions in the presence of atmospheric oxygen [3]. These processes lead to a partial decomposition of PE, i.e. fragmentation of long polyethylene chains into short-chain fragments which are most often ended with functional (carboxyl, ketone, and alcohol) groups [23]. However, sometimes these fragments are still too long to penetrate through the cell wall of microorganisms. For this reason, they are first attacked by extracellular enzymes. Subsequently, by dint of extracellular biosurfactants secreted by microorganisms, polyethylene fragments undergo adhesion to the cell wall and thus easier penetrate inside the cells of microorganisms
[3]. Consequently, the molecular weight of PE is systematically reduced [6, 23]. Studies carried out by Roy et al. [24] showed that two weeks after the addition of prooxidants to polyethylene the material weight loss after abiotic degradation and subsequent degradation with the use of Bacillus pumilus, Bacillus cereus and Bacillus halodenitrificans was $8.4 \%$. Studies carried out by Briassoulis et al. [25] with the use of $20 \mathrm{~mm}$ films with peroxidants showed that, after having been buried for 6 years and 10 months, films underwent a slight fragmentation.

Other methods accelerating the decomposition of polyethylene are: subjecting this polymer to initial abiotic oxidation by thermo- and photo-oxidation, sensitising to hydrolytic degradation or subjecting it to the chemical treatment process [3]. For the first time, the mechanism of biodegradation of low-molecular weight polyethylene fragments was described by Albertson et al. [26]. According to these authors, their biodegradation is similar to B-oxidation of fatty acids and paraffins. $B$-oxidation is a process that involves the oxidation of the hydrocarbon chain of B-carbon. This process' consequence is the removal of further two-carbon acetyl-CoA fragments from the chain and their inclusion in the citric acid cycle whose final products are carbon dioxide and water. Studies on the effect of thermodegradation on the polyethylene decomposition in the presence of Rhodococcus ruber under laboratory conditions were carried out by, among others, Gilan et al. [27]. These authors demonstrated that the temperature factor led to the formation of small-molecule organic acids which were the source of food for microorganisms. As a result of the degradation, the molecular weight of polyethylene increased, which, in turn, proved that shorter polymer chains undergo thermo- and biodegradation as the very first. Other study results were presented by Yamada-Onodera et al. [28], who showed that the earlier chemical and thermal degradation of polyethylene and its subsequent treatments with Penicillium simplicissimum resulted in a significant reduction in its molecular weight. Thus, the authors confirmed that there are microorganisms which are capable of degrading long macromolecules.

In last time, the increasingly used solution to the problem of degradation of polyethylene is its combination with natural polymers, such as starch, cellulose or gelatine [9, 21]. The solution is based on the statement that the combination of a synthetic polymer (resistant to decomposition) with a natural polymer (prone to biodegradation) in one product will give a material whose chemical structure will partially degrade under the influence of biological factors, while its internal structure will be permanently damaged [29]. It can therefore be assumed that if such a composition contains a sufficient amount of a biodegradable component, it is possible that after a certain time, it will be completely degraded. The resulting degradation products will become 
an integral part of the environment and not pose a greater threat to living organisms [23]. However, the intermediate stage in the environment will be micro- and later nanoplastics [30]. Currently, starch is one of the most commonly used plant feedstocks for modifying the structure of polyethylene. This is confirmed by the relatively large number of scientific papers investigating the properties of starch and polyethylene mixtures [5,29-35]. Starch is an easily available and cheap vegetable feedstock and, thanks to its properties, it is widely used in many branches of the economy, above all, in the industry of high-molecular-weight plastics as a biodegradable filler [1]. As it was demonstrated by Broeren et al. [36], the possibility of obtaining starch for the production of biodegradable polymer materials does not only concern plant feedstocks. Starch can also be recovered from sewage, which can significantly affect the economic aspect of its production. Moreover, these authors emphasize yet another very important aspect related to the use of starch, namely the possibility of reducing greenhouse gas emission and nonrenewably energy consumption.

\section{Modification of Polyethylene with Starch}

It was Griffin [37] who in the 1970s began studies on the modification of polyethylene with starch in order to increase its biodegradability. His studies showed that on the one hand, the addition of starch increased the hydrophilicity of polyethylene film and facilitated its oxidation process, but on the other hand, the polymer material lost its durability. For this reason, the next stage of study carried out by Griffin [37] involved coating the starch surface with silane. However, this gave an opposite effect, i.e. increased hydrophobicity of the material. The author perfected the process and, after nearly 20 years of research, he received a composite containing unmodified starch and unsaturated polyethylene. Other studies carried out by Łabużek et al. [38] with the use of polyethylene films modified with polyester (the trade name: "Bionolle ${ }^{\circledR}$ "), obtained in the process of polycondensation of glycols with dicarboxylic acids, showed that the degradation of this composite occurred as a result of removing polyester from the film. Łabużka et al. [38] also demonstrated that up to $30 \%$ additions of polyester resulted in significant changes in the chemical structure of polyethylene. The FTIR spectra analysis carried out by these authors showed the appearance of new bands derived from ketone, ester, aldehyde, and hydroxyl groups, whose presence clearly confirmed degradation of both composite components. In the course of their studies, Kormin et al. [39] discovered significant physical and mechanical changes of low density polyethylene (LDPE) after modifying it with starch obtained from different biomasses. In addition to the significant deterioration of mechanical properties (mechanical resistance, breaking capacity), their study revealed increased water uptake with the increased addition of starch. This conclusion is significant from the point of view of the possibility and rate of biodegradation of the composites produced (Table 1).

A good knowledge of starch properties, resulting from many years of research, finally led to the conclusion that native (unmodified) starch has a very limited application due to its poor solubility, strong hydrophobic properties, as well as unfavourable mechanical properties [33-35]. As stated by Żuchowska et al. [1], the structure of primary starch, i.e. grain size, depends on many factors directly related to the type of plant from which it is obtained, as well as its growing conditions. According to Kormin et al. [39], different properties of starch (used for the preparation of composites from LDPE) and resulting from acquiring it from various plant species may decide on the intended use of the materials obtained. The starch properties are also strongly conditioned by humidity. Considering that starch contains about $70 \%$ of amylopectin and $30 \%$ of amylose on average, and the molecular weight of amylopectin and amylose is $5 \cdot 10^{6} \mathrm{~g} \cdot \mathrm{mol}^{-1}$ and nearly $10^{5} \mathrm{~g} \cdot \mathrm{mol}^{-1}$, respectively, its glass transition temperature can reach about $25^{\circ} \mathrm{C}$ or $62{ }^{\circ} \mathrm{C}$. However, the values of glass transition temperature depend significantly on humidity and, for the given temperatures, the humidity should exceed $20 \%$ or be equal to $15 \%$, respectively. Therefore, these specific properties create many technological difficulties during the preparation of polymer-starch composites [1]. These authors argued that the following are also significant problems: the lack of adhesion at the polymer/ starch grains boundary and low thermal resistance of starch, limiting the number of synthetic polymers whose structure can be modified with starch (Table 2).

As stated by Korol [35], reduced hydrophobicity of starch is possible through its chemical modification, but this process leads to the creation of products toxic to the environment and is expensive. For these reasons, another commonly used method of modifying native starch is its thermoplasticisation in the form of plasticisers during extrusion [35]. This author stated that this process leads to the disruption of the crystalline structure of starch, resulting from breaking of hydrogen bonds and its transformation into an amorphous form of thermoplastic starch, which is fully biodegradable. One of the few disadvantages of this material is sensitivity to moisture and brittleness, but in combination with synthetic polymers, it acts as a factor that increases their susceptibility to degradation [35]. Świerz-Motysia et al. [34] highlighted that the homogeneity and effective compatibility are key parameters affecting the final properties of the polyethylenestarch composite. Modern technological processes allow the introduction of $20-80 \%$ by weight of starch to the composite [33]. Of course, the susceptibility of the polymer-starch composite to biodegradation increases with the 
Table 1 List of microorganisms associated with polyethylene degradation

\begin{tabular}{|c|c|c|c|}
\hline Polymer type & Microorganisms/culture method & $\begin{array}{l}\text { Evaluation of biodegradation (technique/ } \\
\text { observation) }\end{array}$ & References \\
\hline Polyethylene & $\begin{array}{l}\text { Brevibacillus borstelensis, Comamonas acido- } \\
\text { vorans TB-35, Pseudomonas chlororaphis, } \\
\text { P. aeruginosa, P. fluorescens, Rhodococcus } \\
\text { erythropolis, R. rubber, R. rhodochrous, } \\
\text { Staphylococcus cohnii, S. epidermidis, S. } \\
\text { xylosus } \\
\text { Streptomyces badius, S. setonii, S. viridospo- } \\
\text { rus, Bacillus amyloliquefaciens, B. brevis, } \\
\text { B. cereus, B. circulans, B. circulans, B. } \\
\text { halodenitrificans, B. mycoides, B.pumilus, } \\
\text { B. sphaericus, B. thuringiensis, Arthrobac- } \\
\text { ter paraffineus, A. viscosus, Acinetobacter } \\
\text { baumannii, Microbacterium paraoxydans, } \\
\text { Nocardia asteroides, Micrococcus luteus, } \\
\text { M. lylae, Lysinibacillus xylanilyticus, } \\
\text { Aspergillus niger, A. versicolor, A. flavus, } \\
\text { Cladosporium cladosporioides, Fusarium } \\
\text { redolens, Fusarium spp. AF4, Penicillium } \\
\text { simplicissimum YK, P. simplicissimum, } \\
\text { P. pinophilum, P. frequentans, Phanero- } \\
\text { chaete chrysosporium, Verticillium lecanii, } \\
\text { Glioclodium virens, Mucor circinelloides, } \\
\text { Acremonium Kiliense, Phanerochaete } \\
\text { chrysosporium }\end{array}$ & $\begin{array}{l}\text { FTIR (Visual changes in the polymer struc- } \\
\text { ture), SEM, plate assay and } \mathrm{CO}_{2} \text { production, } \\
\mathrm{CO}_{2} \text { evolution test }\end{array}$ & {$[16,40-44]$} \\
\hline Low density polyethylene film & $\begin{array}{l}\text { Aspergillus spp., Fusarium spp., Aspergillus } \\
\text { Versicolor, Microbacterium spp., Pseu- } \\
\text { domonas putida, Bacterium, Pseudomonas } \\
\text { aeruginosa, Aspergillius fumigatus, Penicil- } \\
\text { lium spp., (Fusarium spp., Penicillium spp., } \\
\text { Mucor spp., Aspergillus niger, A. japonicas } \\
\text { and A } \\
\text { flavus }\end{array}$ & $\begin{array}{l}\text { SEM, FTIR, } \mathrm{CO}_{2} \text { Evolution test, DSC (Difer- } \\
\text { ential scanning } \\
\text { calorimetry), Weight loss study }\end{array}$ & [45-49] \\
\hline High-density polyethylene (HDPE) & Arthrobacter sp. and Pseudomonas sp & SEM, FTIR & {$[50]$} \\
\hline
\end{tabular}

Table 2 Various polymer degradation routes $[16,51]$

\begin{tabular}{llll}
\hline Factors (requirement/activity) & Photo-degradation & Thermooxidative degradation & Biodegradation \\
\hline $\begin{array}{l}\text { Active agent } \\
\text { Requirement of heat }\end{array}$ & UV-light or high-energy radiation & Heat and oxygen & Microbial agents \\
& Not required & $\begin{array}{l}\text { Higher than ambient required } \\
\text { temperature }\end{array}$ & Not required \\
Rate of degradation & Initiation is slow. But propagation is fast & Fast & Moderate \\
Other consideration & $\begin{array}{l}\text { Environment friendly if high-energy } \\
\text { radiation is not used }\end{array}$ & $\begin{array}{l}\text { Environmentally not } \\
\text { acceptable }\end{array}$ & Environment friendly \\
Occeptable but costly & & Not acceptable & Cheap and very much \\
& & & acceptable \\
\hline
\end{tabular}

increasing proportion of starch. Apart from the addition of thermoplastic starch, the degradability of polyethylene is more commonly increased by enriching its structure with a compatibiliser. This material not only contains reactive functional groups, but also increases interfacial adhesion and compatibility of the mixture of polyethylene and thermoplastic corn starch [34].

\section{(Bio)degradation of Polyethylene Polymer Materials}

Studies on the addition of biodegradable starch as a filler of polymers, which is an easily assimilated carbon source for microorganisms were carried out by, among others, 
Chandra and Rustugi [52], as well as Boryniec et al. [29]. The authors mentioned above confirmed that the addition of starch significantly affects the rate of degradation of polymer materials, which, after using this component from the material structure by microorganisms, lose their integrity. On the other hand, Austin [53] determined under laboratory conditions that after 10 months, the structure of polyethylene containing $6 \%$ addition of starch does not change at all. Similar results were obtained by Johanson et al. [54], who tested the degradability of polyethylene films containing 5-9\% of starch under the composting process conditions and showed only a slight degradation of polyethylene. These authors obtained greater changes in the surface structure of the tested films. Studies involving higher addition of starch to polyethylene films were carried out by Żakowska et al. [32]. The authors demonstrated that the introduction of $10-30 \%$ dose of starch into polyethylene resulted in significant changes in the film structure after its 6-month incubation in soil. As part of the same project, Boryniec et al. [29] confirmed changes in polyethylene structure at the supramolecular level by the X-ray scattering (SAXS) method. Another form of polyethylene structure modification is the addition of mineral compounds. Such research was carried out by Szumigaj-Tarnowska et al. [21]. These authors evaluated changes in the physical properties of polyethylene films modified with mineral compounds (dolomite, calcite) after 12-month degradation of these materials in soil incubated in two temperature ranges $\left(30{ }^{\circ} \mathrm{C}\right.$ and $\left.45^{\circ} \mathrm{C}\right)$. SEM images obtained by Szumigaj-Tarnowska et al. [21] showed that the incubation of polymer materials enriched with mineral compounds at none of the temperatures caused changes in their surface structure. However, the incubation temperature increase to $45^{\circ} \mathrm{C}$ intensified the microbiological processes and increased the number of microorganisms forming the biofilm on the film surfaces.

The important role of biofilms in the decomposition of polymer materials was noted by Gilan et al. [27] as well as Mohan and Srivastava [23]. According to these authors, the colonisation of the surface of polymer materials by microorganisms which contribute to the formation of biofilms on their surface is a prerequisite for starting the initial decomposition of these materials. Biofilm is a non-adhesive protective layer for various types of bacteria, consisting in 80-95\% of a hydrated matrix of biopolymers and water, which give it a spatial character. As reported by Mohan and Srivastava [23], covering the surface of polymer with a biofilm layer can cause its micro-swelling and, as a consequence, lead to the loss of mechanical stability of polymer material. Thus, the disturbed structure of the polymer surface can become more susceptible to the action of microorganisms. However, Arutchelvi et al. [7] highlighted that the polymer degradation rate clearly depends on the type of their surface, i.e. polymers with a rough (non-homogeneous) surface are faster degraded than those with a smooth one.

The study examples presented above are an expression of the aspiration to reduce the nuisance of polymer materials for the natural environment and emphasise the importance of processes supporting the protection of the natural environment. For this reason, the development of modern and waste-free (the so-called 'clean') technologies, minimising the emission of pollutants into the environment, has been observed in recent years, in addition to the analysis of ecological threats [33]. The broadly understood recycling of polymer materials, mentioned at the beginning of the chapter, is considered one of the most ecological and rational solutions $[5,16]$.

\section{The Management of Post-consumer Polymer Materials}

\section{Energy Recycling}

The literature data show that in the highly developed countries of the European Union, the dominant method of dealing with polymer material waste is their energy recycling, i.e. combustion with energy recovery $[2,12]$. This method is especially popular in Switzerland where about $90 \%$ of waste is thermally converted [12]. Stachurek [2] reported that nearly $10 \%$ of the initial waste volume is generated as a result of a combustion process and it can no longer be used again. Thermal conversion is carried out at up to $1000{ }^{\circ} \mathrm{C}$ for approx. $2 \mathrm{~h}$, and the heat obtained from this process can be used for the production of thermal energy or electricity $[2,33]$. According to data published by PlasticsEurope [12], only $16 \%$ of polymer material waste is currently combusted with energy recovery in the world, and just over $4 \%$ without energy recovery. Unfortunately, besides the reduction of waste mass and partial energy recovery, this method can pose a significant threat to the environment. During the combustion of polymer materials, waste gases are formed, which contain many toxic and harmful substances [2, 55]. These substances include toxic hydrocarbon oxides and particularly hazardous dioxins $\left(\mathrm{C}_{4} \mathrm{H}_{8} \mathrm{O}_{2}\right)$ and furans $\left(\mathrm{C}_{4} \mathrm{H}_{4} \mathrm{O}\right)$, which pose a serious threat to the environment and human health [2]. However, there are reports stating that carbon monoxide (CO) is the most dangerous and most common gas present in the combustion products of polymer materials. Additionally, depending on the type of polymer material, other compounds, such as: carbon dioxide $\left(\mathrm{CO}_{2}\right)$, hydrogen cyanide $(\mathrm{HCN})$, hydrogen chloride $(\mathrm{HCl})$, phosgene $\left(\mathrm{COCl}_{2}\right)$, phosphine $\left(\mathrm{PH}_{3}\right)$, NOx and SOx, phenol, or formaldehyde can be formed $[39,56]$. Therefore, the applicable regulations require the installation owners to mount the so-called afterburner chambers in which products generated during the 
process will be burned. The afterburning of exhaust gases is aimed at reducing the concentration of toxic substances to contents regulated by legal requirements $[2,56]$. However, these authors highlighted that the afterburning of gases reduces the energy efficiency of the process and significantly increases the costs associated with the exhaust gases purification. As stated by Dacko [33], thermal utilisation of polymer materials is much more difficult due to their diversity and costs 6 times more on average than organic recycling.

\section{Organic Recycling}

One of the methods of organic recycling is composting. It is a biochemical process of transforming materials under controlled conditions with the participation of aerobic microorganisms in various temperature ranges [2, 11, 14, 57, 58]. Three main phases of this process can be distinguished: mesophilic, thermophilic, and the compost stabilisation phase $[58,59]$. The final products of biological transformation of biomass are: water, carbon dioxide, and a relatively stable fraction of organic matter $[11,14,58,60]$. The introduction of new generation polymer materials into the composting process, i.e. containing biocomponent derived from natural feedstocks, may not only improve the structure of composted biomass, positively affecting the rate and direction of the process, but also prevent the formation of waste from polymer materials and the release of environmentally dangerous emissions [14, 60, 61]. This solution is additionally supported by savings in the natural resource management and reduced burden on the natural environment, resulting from smaller amounts of polymer waste deposited in municipal waste landfills [5, 11, 33]. The suitability of artificial polymer for biological transformation is confirmed by the certification process.

However, the introduction of polymer materials with the addition of plant biocomponent into the composting process is dependent on many factors that result mainly from the specific properties of polymer materials [14]. First of all, the problem of biological transformation of polymer materials with biocomponent may be due to difficulties with their proper preparation to the process, i.e. their fragmentation to increase the area inhabited by microorganisms [60]. Secondly, one should take into account the possibility of forming intermediate substances during polymer material decomposition, able to limit the enzymatic activity of microorganisms. This thesis is partially confirmed by the studies of Mierzwa-Hersztek et al. [62]. Although the results obtained by these authors do not directly concern microorganisms active in the composting process, they clearly show that extracts from composts with the addition of polymer materials produced from polyethylene and maize starch inhibited the linear growth of fungi. Therefore, the addition of polymer materials to the composted biomass should be performed so that it does not lead to deterioration of optimal process conditions [23, 63]. One of the most important factors conditioning the proper composting process is the $\mathrm{C} / \mathrm{N}$ ratio, which, according to the literature, should be approx. $30 / 1[14,59,64]$. Such a C/N ratio in biomass prepared for composting significantly affects the metabolic activity of microorganisms and thus the composting effectiveness. It can be of great importance for the addition of polymer materials. Kim and Rhee [57] noted that the limited availability of a key energy component, i.e. carbon, or a key structure component, i.e. nitrogen, for microorganisms may reduce their activity and slow down their metabolic processes.

Many authors admitted that the compost environment creates the best conditions for the polymer material decomposition (temperature, high humidity, presence of various physiological groups of microorganisms, air, changing $\mathrm{pH}$, access of light) $[2,11,14,16,64,65]$. These authors argued that, undoubtedly, water is the most important factor in the environmental degradation of polymers among these mentioned above. However, its effect depends on the physical and chemical properties, as well as reactivity of polymer material. On the one hand, according to Adamcová and Vaverková [65], the presence of water causes the hydrolysis of a bond between polymer and filler and promotes the formation of hydroxyl radicals or other reactive groups initiating free radical reactions. On the other hand, the presence of water is crucial for the development of microorganisms and favours enzymatic reactions causing microbiological degradation $[6,16,23]$.

In the European Union, the suitability of packaging for organic recycling (composting) is confirmed on the basis of PN - EN 13432:2002 [66], which is harmonised with Directive 94/62/EC. In the scope of the standard there are procedures determining the suitability for composting and processing of packaging and packaging materials under anaerobic conditions. Four properties are taken into account: (1) biodegradability, (2) fragmentation during biological processing, (3) impact on the biological processing, (4) impact on the quality of the compost obtained. Also, certification systems are introduced due to the complexity of procedures related to the assessment of packaging material carried out in terms of biodegradation and its further use in the composting process.

\section{Material Recycling}

It is based on the use of post-consumer polymer materials in the production of new items. An important element of material recycling is the system of separate collection of plastics. The collection of plastics is a great problem throughout the whole recycling chain. Making the society aware of the problem and finding the way to motivate it is enormously important here, as with this method, it is possible to 
recover materials with relatively small expenditure on the material sorting and cleaning. On the other hand, there is a rapid development of automatic separation with the use of optoseparators, which may increase the obtained purity of polymer waste. Materials obtained in this way can be a valuable raw material, not much different in properties from the original material [67].

\section{Chemical Recycling}

Chemical recycling involves treating polymer material with water or other chemical compounds under conditions of elevated pressure and temperature, which leads to the formation of low molecular weight compounds constituting a valuable raw material for the re-obtaining of, among others, pure polymers [68].

\section{Types and Factors Affecting the Degradation of Polymers}

The susceptibility of polymer materials to decomposition depends not only on environmental conditions ( $\mathrm{pH}$, temperature, air availability, humidity) and physiological diversity of individual groups of microorganisms colonising their surface, but also on their chemical structure (molecular weight, number and type of bonds, crystallinity) $[6,7,21$, 23, 26, 51] (Table 2). Literature data indicate that amorphous polymers with a linear structure are subject to faster degradation, and that crystalline polymers with branched structure are decomposed much slower $[8,26]$. Heterochain and hydrophilic polymers as well as polymers with higher flexibility and low molecular weight are also more prone to decomposition. The type of functional groups present in polymer is also an important criterion. Depending on the degree of microbial degradation, it can be arranged as follow: ester $>$ etheric $>$ amide $>$ urethane [2]. The aging of the material should also be taken into account, which, although very slow, leads to significant structural changes in polymer [69]. Pająk et al. [8] distinguished the following types and factors affecting the degradation of polymers:

- thermal degradation-caused by elevated temperature,

- photodegradation - caused by solar radiation,

- thermooxidative degradation — caused by air,

- oxidative degradation-caused by molecular oxygen, atomic oxygen, and ozone,

- radiation degradation-caused by ionising radiation,

- ultrasonic degradation - caused by ultrasounds,

- hydrolytic degradation-caused by water, acids, and bases,

- corrosion degradation—caused by acids, bases, strong oxidants, chemical compounds,
- atmospheric degradation-caused by atmospheric conditions,

- mechanical degradation-caused by mechanical forces (rolling, stretching, grinding),

- biodegradation - caused by biological factors (microorganisms).

\section{Stages of Polymer Material Decomposition}

The decomposition of polymer materials is complex under natural conditions and, therefore, it is impossible to indicate one factor or mechanism responsible for this process [63]. Usually, the process occurs due to the presence of several simultaneous and synergistic factors and runs in several stages. The first stages take place outside the bacterial cell and usually involve many physical, chemical, and biological factors listed by Pająk et al. [8], which result in the change and deterioration of the basic material properties (folding, breaking, fragmentation, etc.) [65]. These changes are caused by shortening of the polymer chain (depolymerisation) and thus the reduction of the polymer molecular weight (Fig. 2). In the next stages, the resulting products of the polymer decomposition process: oligomers, dimers, (water-soluble) monomers, can pass the semipermeable cell membrane and be used as a source of carbon (energy) for microorganisms [6]. Carbon dioxide and water, being completely safe for the environment, are the final products of mineralisation of intermediate polymer degradation products by microorganisms [2].

Although polymer material degradation does not relate to the microbiological world exclusively, microorganisms are among the most important (bio)degradation factors in nature [2]. According to Pathak and Navneet [61] biological agents and their methabolic products (enzymes) can be used as tools in the polymer degradation. According to these authors, bacterial and fungal species are the most abundant

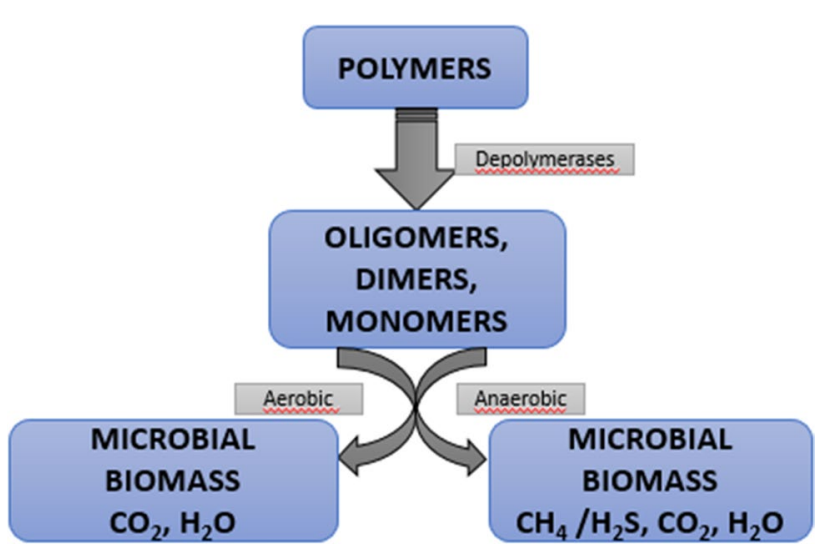

Fig. 2 Reaction pathways during degradation of polymers 
biological agents found in nature and have distinct degradation abilities for natural and synthetic polymers. According to Kale et al. [40], bacteria and fungi are microorganisms that play the greatest role in the biological degradation of polymers. The authors stated that the predominance of microorganisms over abiotic factors is due to the fact that they have genetic and physiological adaptation mechanisms enabling degradation of completely new and, sometimes, theoretically resistant polymer compositions.

Decomposition of compounds contained in polymer materials occurs as a result of metabolic processes, i.e. biochemical reactions which are catalysed by enzymes produced by microorganisms [65]. As indicated by Mohan and Srivastava [23], the presence of polymer induces or increases the microbial (especially extracellular) synthesis of enzymes. Once they are released into the environment and adsorbed on the surface of polymer material, these enzymes lead to its enzymatic degradation, mainly as a result of hydrolysis. However, it should be noted that in the case of polymer materials containing in their structure the addition of plant component, including starch, the material decomposition primarily involves the removal of starch grains by microorganisms surrounding the material $[7,8,23]$. The limiting factor are the material thickness and the degree of starch granules coating. The removal of starch from polymer material weakens its cohesiveness, increases its surface-tovolume ratio and leads to loosening of the polymer material structure. In places with decomposed starch, free spaces are created, which become active centres for further material degradation factors [40]. This theory is confirmed by the studies of Pająk et al. [8], who proved that the decomposition of polyethylene material containing $15 \%$ of starch and vegetable oil occurs in two stages, and starch and vegetable oil are photoinitiators in soil. The authors claimed that starch and vegetable oil removed from the polyethylene structure are transferred to the soil in close proximity to the material. Photoinitiators then come in contact with metal salts present in the soil. This, in turn, leads to the formation of peroxides that cause degradation of the polyethylene chain.

However, the complete degradation of currently produced polymer materials under composting conditions is relatively rare or insignificant, which is confirmed by numerous scientific reports $[21,29,53,54,60,70,71]$. This is caused not only by the very complex, diverse, and specific structure of polymer materials, but also the time required for their complete degradation [2]. Given that composting can last several months depending on feedstocks used in the process $[59,60,70]$, and the polymer material degradation usually lasts from a few to several decades [23], the composting should be treated as a process supporting degradation of this type of materials before their further (natural) use. Similar studies were carried out by Dave et al. [72] after introducing polyethylene films (mixed with compost at 1:1 ratio), which contained $25 \%$ and $30 \%$ addition of starch, into the soil. These authors demonstrated that during 48-week incubation, there was a loss in the weight of film with $25 \%$ and $30 \%$ additions of starch, by $3.18 \%$ and $8.36 \%$, respectively. The next stage of the study conducted by Dave et al. [72] involved the incubation of polymers separated from soil with microorganisms cultures (Bacillus, Streptomyces, and Aspergillus) isolated from previously composted materials. The application of such an inoculum caused that, after the next 6 weeks of incubation, the weight loss of polyethylene films with $25 \%$ and $30 \%$ additions of starch was $11.2 \%$ and $68.9 \%$, respectively. The composting process of plant biomass with $5 \%$ addition of polymer materials with different polyethylene content and thermoplastic corn starch was also carried out by Mierzwa-Hersztek et al., Mierzwa et al. [62, 70] and Gondek et al. [60]. The authors demonstrated that due to microbiological diversity and elevated temperature, the composting process creates an active degradation environment for polymer materials. However, composts produced with the addition of polymer materials with lower polyethylene content have better physical, chemical, and biological parameters. These authors also carried out 2-year field studies on soils with diverse properties, in which they applied composts with the addition of polymer materials (unpublished data). They showed that the increase in the share of plant biocomponent in the polymer material structure promotes its degradation in the environment under the influence of biotic and abiotic factors. However, the authors mentioned above did not demonstrate a clear effect of composts amended with polymer materials on the yield and chemical composition of perennial ryegrass. Unfortunately, the subject literature lacks other reports on the application of composted polymer materials in agriculture or for soil reclamation purposes. The researchers' concerns are valid taking into account the absence of the possibility to determine the time limit for polymer degradation in the soil environment. This is due to the diversity of polymers, their chemical and physical properties. The adopted 6-month limit for degradation in the composting process is, in many cases, only the beginning of the process. The fundamental questions are what is the size of oligomers that could be introduced into the soil environment, how long would it take for complete biodegradation to occur in this environment, and whether the various plasticisers used are the source of additional pollution.

\section{Conclusions and Future Research}

The subject literature shows that previous studies focused primarily on the assessment of changes in the properties of various types of polymer materials in the composting process $[14,64]$, after introducing into the soil $[27,28]$ or on a simultaneous comparison of the composting process and 
the effect of the soil environment on the polymer material degradation [73]. Also Gauthier et al. [74] and Vargla et al. [75] emphasised the fact that the majority of previous tests to determine the degree of polymer material degradation were carried out under controlled conditions and that the information relating to natural conditions is very limited, as such tests usually concern the possibility of using polymer materials for agricultural crops under protective covers. Gauthier et al. [74] argued that this is caused by the difficulty to determine the impact of individual environmental factors (e.g. geographical location, weather conditions, use of fertilisers and plant protection products) on the rate of polymer material degradation. These authors suggested that the variability and severity of different environmental factors (e.g. precipitation, wind, frost, solar radiation) and factors associated with the intended human activity are not taken into account under laboratory conditions. Gauthier et al. [74] also emphasised that the soil properties, the transformation of organic matter and the trace element in particular, have a significant effect on the degree of polymer material degradation. The latest literature shows that there are already studies on the use of biodegradable mulches in agricultural production systems [62, 76]. Bandopadhyay et al. [76] indicated that mulches obtained from polyethylene must be removed from the soil, while biodegradable mulches may remain in it. However, there are many doubts and uncertainties about the effect of this type of materials on soil ecosystem, especially in the long term. According to Bandopadhyay et al. [76] biodegradable mulches potentially influence soil microbial communities in two ways: first, as a surface barrier prior to soil incorporation, indirectly affecting soil microclimate and atmosphere (similar to PE films) and second, after soil incorporation, as a direct input of physical fragments, which add carbon, microorganisms, additives, and adherent chemicals.

The facts presented above prove that knowledge of the conditions determining the decomposition of polymer materials and their impact on the natural environment is still insufficient. The recent literature reports reveal many contradictory theories, especially those that relate to the degradation of polymer materials in the soil environment. One should also note that the vast majority of studies do not take into account the vegetation effect on the decomposition of polymer materials in soil. For this reason, there is a real need for a comprehensive assessment of the effect of polymers with modified primary structure on the composting process as well as the effect of the application of compost with the addition of polymer material under natural conditions. The authors are aware of the hazards to humans caused by microand nanoparticles, and thus products of incomplete degradation. However, one should remember that artificial polymers will be introduced into the agricultural environment consciously, as in the case of compost from municipal waste or coated seeds. It is important, despite the current lack of permission to introduce polymers into the environment, to learn about the time and cycle of degradation products in the environment.

Acknowledgements The Research was financed by the Ministry of Science and Higher Education of the Republic of Poland. The research was implemented within the framework of the BIOMASA project (POIG 01.01.02-10-123/09), partially financed by the European Union with the European Regional Development Fund.

Open Access This article is distributed under the terms of the Creative Commons Attribution 4.0 International License (http://creativeco mmons.org/licenses/by/4.0/), which permits unrestricted use, distribution, and reproduction in any medium, provided you give appropriate credit to the original author(s) and the source, provide a link to the Creative Commons license, and indicate if changes were made.

\section{References}

1. Żuchowska D et al (2007) Polymers 52:524-531

2. Stachurek I (2012) Sci High Schools Work Prot Manag Katowice 1:74-108

3. Koutny et al (2006) Chemosphere 64:1243-1252

4. Penczek et al (2013) Polymers 11-12:835-837

5. Vázquez-Morillas et al (2016) J Polym Environ 24:221-229

6. Gu J-D (2003) Intern Biodeter Biodegrad 52:69-91

7. Arutchelvi et al (2008) Ind J Biotech 7:9-22

8. Pająk et al (2009) Ecol Probl 13(3):154-158

9. Pasieczna-Patkowska S, Lesiuk A (2013) Chemik 67:863-872

10. Lambert S, Wagner M (2017) Chem Soc Rev 46:6855-6871

11. Herman B et al (2010) Proceed of ECOpole. 4:133-140

12. Association of plastics manufacturers, plastics - the facts (2017) An analysis of European plastics production, demand and waste data. Plastics Europe, 1-44. http://www.plasticseurope.org/appli cation/files/5715/1717/4180/Plastics_the_facts_2017_FINAL for_website_one_page.pdf

13. Avella $\mathrm{M}$ et al (2001) Polym Test 20:517-521

14. Iovino R et al (2008) Polym Degrad Stab 93:147

15. Malinowski R (2015) Eng Environ Prot 18(2):215-231

16. Shah AA et al (2008) Biotechnol Adv 26:246-265

17. NWMP (2016) National waste management plan, Polish monitor Warsaw, pp 259

18. Schirmel J et al (2018) Appl Soil Ecol 124:379-393

19. Geyer R et al (2017) Sci Adv 3:e1700782

20. Rejewski P, Kijeński J (2010) Polymers 55:711-717

21. Szumigaj-Tarnowska J et al (2011) Chem Did Ecol Metrol $16: 35-40$

22. Muñoz K et al (2017) Appl Soil Ecol 113:36-44

23. Mohan KS, Srivastava T (2010) J Biochem Tech 2:210-215

24. Roy PK et al (2008) Polym Degrad Stab 93:1917-1922

25. Briassoulis D et al (2015) Appl Polym Sci 132:1-20

26. Albertson AC et al (1987) Polym Degrad Stab 18:73-87

27. Gilan I et al (2004) Appl Microbiol Biotechnol 65:97-104

28. Yamada-Onodera K et al (2001) Polym Degrad Stab 72:323-327

29. Boryniec S et al (2004) Polymers 49:424-431

30. Qi Y et al (2018) Sci Tot Environ 645:1048-1056

31. Johansson $\mathrm{M}$ et al (1999) Biol Fert Soils 30:160-167

32. Żakowska $Z$ et al (2003) 3rd conference sciences. Distribution and microbiological corrosion of technical materials Lodz 279-286

33. Dacko P et al (2008) Ecol Probl 12:39-42

34. Świerz-Motysia B et al (2011) Polymers 56:271-280 
35. Korol J (2014) Przem Chem 93:457-463

36. Broeren MLM et al (2017) Res Cons Rec 127:246-255

37. Griffin GJL (1977) Patent: 4016117, USA https://patents.googl e.com/patent/US4016117A/en

38. Łabużek $S$ et al (2005) Polymers 50:675-681

39. Kormin $\mathrm{S}$ et al (2017) International research and innovation summit series. Mater Sci Eng 226:1-9

40. Kale SK et al (2015) J Biochem Tech 6:952-961

41. Dussud C, Ghiglione JF (2014) Bacterial degradation of synthetic plastics. In CIESM Workshop Monogr 46:49-54

42. Grover A et al (2015) Int J Environ Sci 5:1091-1105

43. Restrepo-Flórez JM et al (2014) Int Biodeterior Biodegrad 88:83-90

44. Bhardwaj H et al (2012) Sci Rep 1:1-4

45. Das MP, Kumar S (2015) 3 Biote 5:81-86

46. Sindujaa $P$ et al (2011) Water Res J BiolSci 6:141-145

47. Negi $\mathrm{H}$ et al (2011) Biologija 57:141-147

48. Singh V et al (2012) Asian J Exp Biol Sci 3:498-501

49. Singh J, Gupta KC (2014) Int J Curr Microbiol Appl Sci $3: 443-448$

50. Balasubramanian V et al (2010) India Lett Appl Microbiol 51:205-211

51. Muthukumar A, Veerappapillai S (2015) Int J Pharm Sci Rev Res 31:204-209

52. Chandra R, Rustugi R (1998) Progres Polym Sci 23:1273-1335

53. Austin RG (1990) In: ed. Barenberg SA et al Degradable materials: perspectives, issues and opportunities. CRC Press, Boca Raton, $\mathrm{p} 20$

54. Johanson KE et al (1993) Appl Environ Microbiol 59:1155-1161

55. Hryb W (2008) Arch Waste Manag 10:55-64

56. Iwko J (2007) Mechanic 10:1-3

57. Kim DY, Rhee YH (2003) Appl Microbiol Biotechnol 61:300-308
58. Neklyudov AD et al (2008) Appl Bioch Microbiol 44:6-18

59. Jędrczak A (2007) Biological waste treatment. PWN, Warsaw, p 456

60. Gondek K et al (2015) Pol J Environ Stud 24:2397-2403

61. Pathak VM, Navneet (2017) Biores Bioproc 4:1-31

62. Mierzwa-Hersztek M et al (2018) Sci Tot Environ 635:1063-1075

63. Siotto M et al (2011) Water Air Soil Pollut 221:245-254

64. Ishigaki T, Sugano W, Nakanishi A, Tateda M, Ike M, Fujita M (2004) The degradability of biodegradable plastics in aerobic and anaerobic waste landfill model reactors. Chemosphere 54:225233. https://doi.org/10.1016/S0045-6535(03)00750-1

65. Adamcová D et al (2015) Pol J Environ Stud 24:1497-1505

66. PN-EN 13432:2002 standard: packaging-requirements for packaging recoverable through composting and biodegradation-test scheme and evaluation criteria for the final acceptance of packaging

67. Fortelny I et al (2004) Polym Degrad Stab 85:975-979

68. Lopez-Fonseca R et al (2010) Polym Degrad Stab 95:1022-1028

69. Mizushima $\mathrm{M}$ et al (2014) Polymer Test 38:81-86

70. Mierzwa $\mathrm{M}$ et al (2014) Chem Indus 93:321-325

71. Kopeć M et al (2016) Ecol Chem Eng S 23(1):143-154

72. Dave $\mathrm{H}$ et al (1997) World J Microbiol Biotechnol 13:655-658

73. Husarova L et al (2010) Polym Degrad Stabil 95:1794-1799

74. Gauthier E et al (2015) J Appl Polym Sci pp. 10

75. Vargla V (2016) Period Polytech Chem Eng 60:60-68

76. Bandopadhyay S et al (2018) Front Microbiol 9:1-7

Publisher's Note Springer Nature remains neutral with regard to jurisdictional claims in published maps and institutional affiliations. 